\title{
Effectiveness of attention bias modification by computerized attention training on reducing social anxiety of adolescents
}

\author{
Hassan Shafiei ${ }^{1 *}$ iD , Hossein Zare $^{2}$ \\ 1. Assistant Professor of Psychology Department, Payame Noor University, Tehran, Iran \\ 2. Professor of Psychology Department, Payame Noor University, Tehran, Iran
}

Recieved: 8 May 2018

Revised: 27 Aug. 2018

Accepted: 28 Aug. 2018

Keywords

Adolescents

Social anxiety

Attentional bias

Attention bias modification (ABM)

Computerized attention training

Corresponding author

Hassan Shafiei, Assistant Professor of Psychology, Payame Noor University, Tehran, Iran

Email: H_shafiee@pnu.ac.ir

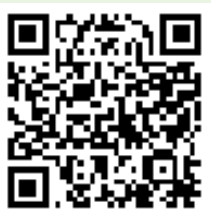

\section{Abstract}

Introduction: Social anxiety is one of the most common mental disorder among adolescents. Recent developments in the treatment of anxiety disorders have been attention bias modification (ABM). The aim of this study was to determine effectiveness of ABM using computerized attention training in reducing social anxiety and attentional bias in adolescents.

Methods: In this study, we used an experimental pretest and posttest design with control group. Thirty-two high social anxious adolescent girls and boys aged 12-17 years, who met all inclusion criteria to be enrolled in the study were selected by using the multistage cluster random sampling method and then randomly divided into two 16-participat groups: attention training group ( $\mathrm{ATG}, \mathrm{N}=16$ ) and control group $(\mathrm{CG}, \mathrm{N}=16)$. In $\mathrm{ATG}$, the participants performed computerized attention training using modified dot-probe task designed to facilitate attentional disengagement from disgusted faces or a control dot-probe task group. In control group, the participants conducted the unmodified dot-probe task. Results: After eight, twice-weekly computer sessions of training, the participants in the attention-training group compared to the control group, showed a significant decrease in attentional bias for disgusted faces and self-reported of social anxiety from pre- to post-assessment.

Conclusion: The results support cognitive models of social anxiety and causal role of attentional bias in development and maintenance of social anxiety. The finding of the current research clearly indicate that use of computerized attention training procedures can be a promising alternative or complementary intervention in treatment of social anxiety. 


\title{
اثربخشى اصلاح سوتيرى توجه با استفاده از آموزش توجه راياناى در كاهش اضطراب اجتماعى نوجوانان
}

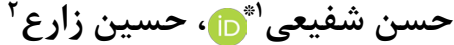

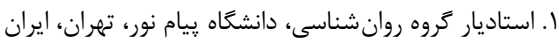

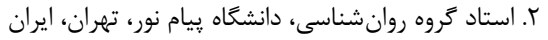

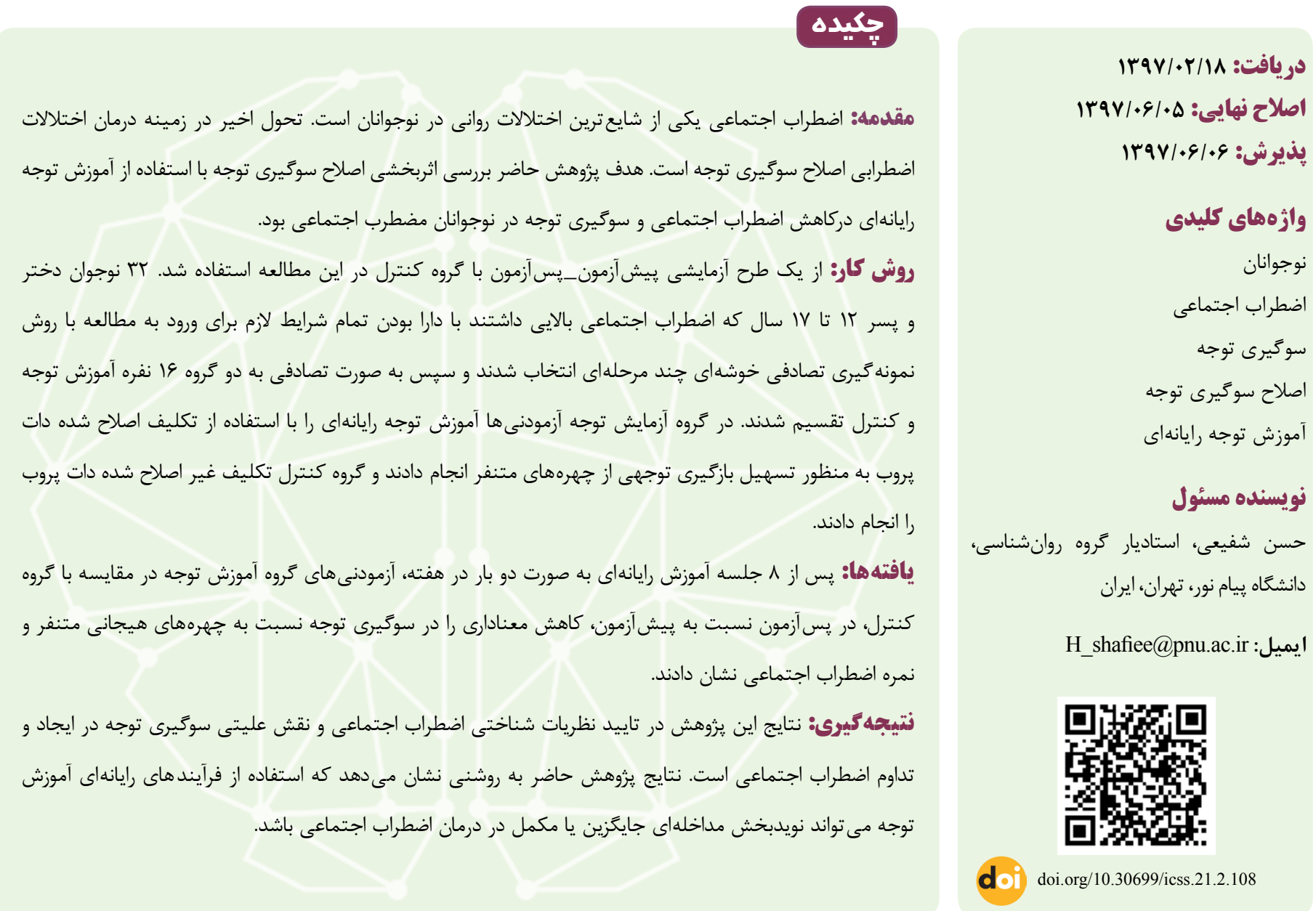

مقدمه

اختلال اضطراب اجتماعى به ترس آشكار و وِيوسته از موقعيتهاى و نوجوانى است (ك). مطالعاتى كه به بررسى الكَىى تحولى اضطراب

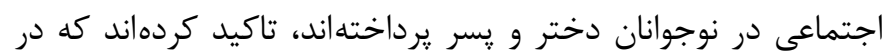
اجتماعى يا عملكردى اشاره دارد و از اين باور فرد ناشى مى شود كه دوره نوجوانى تجربه اضطراب اجتماعى به طور فزايندهاى افزايش او در اين موقعيتها به طرز خجالتآور يا تحقيرآميزى عمل خواهد

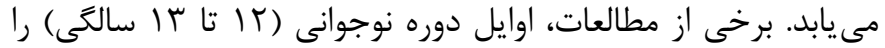
كرد ( ). اختلال اضطراب اجتماعى اختلالى شايع و ناتوان كننده است. دوره ظهور دلمشغولى هاى مضطربكننده دانستهاند (با). نظريههاى اضطراب اجتماعى يكى از سه اختلال شايع تشخيصى در دروه كودكى 
مى كند (1). مداخلات آموزش توجه داراى شواهد اوليهاى هستند كه نشان دهنده كارآمدى آنها در درمان اضطراب است (با). مطالعات متعددى اثرات تكاليف آموزش توجه روى مقادير توجه هيجانى در

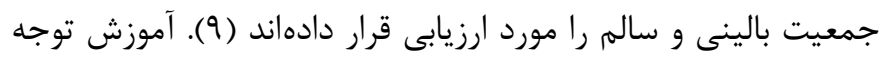

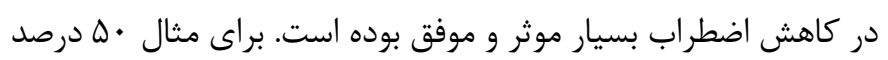

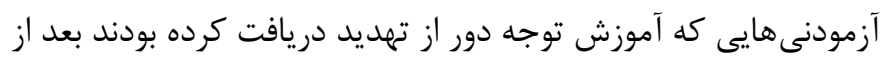

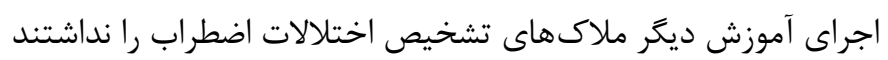

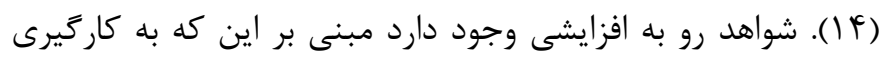
جنين تكاليفى براى ايجاد سوكيرى توجهى مثبت (آموزش اجتناب

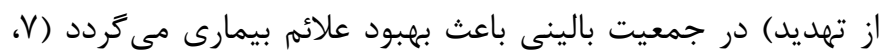

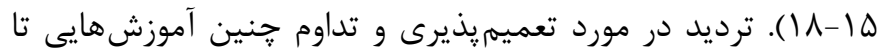

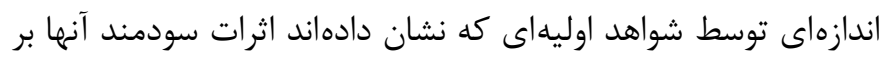

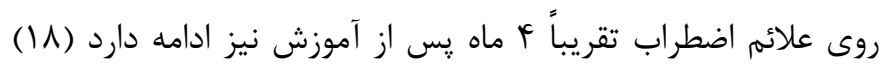

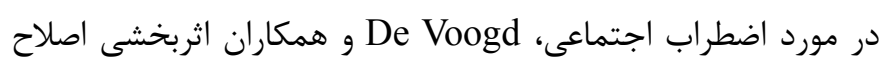

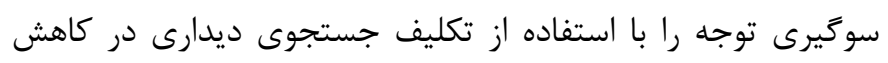

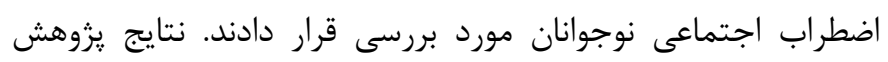

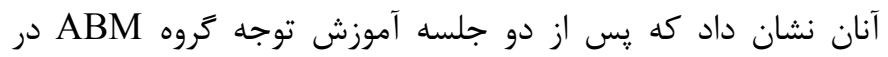
مقايسه با گروه كنترل، كاهش معنادارى را در سوكيرى توجه نسبت به آنه اطلاعات منفى و اضطراب اجتماعى خود كزارش دادند (9 (1). Sportel

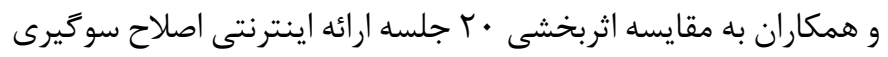
شناختى (Cognitive bias modification (CBM) و و • •

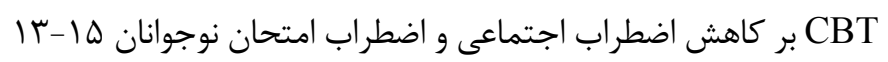

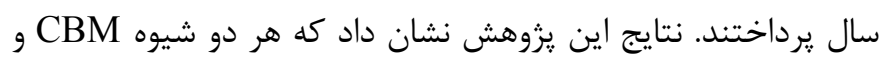

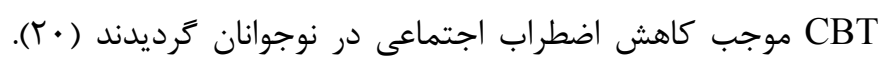
Boettcher

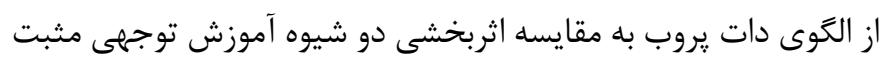
و منفى در آزمودنى هاى داراى اختلال اضطراب اجتماعى يرداختند.

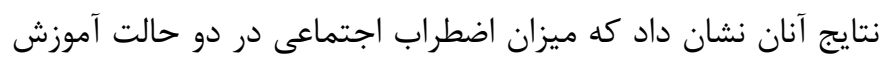

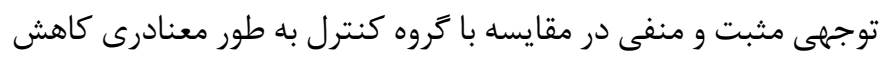

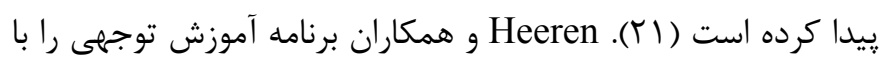

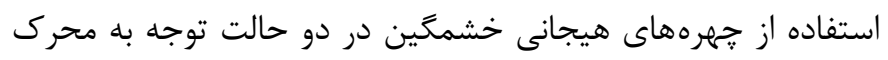
تهديد و توجه به محرك مثبت بر روى آزمودنى هاى داراى آدئ اختلال

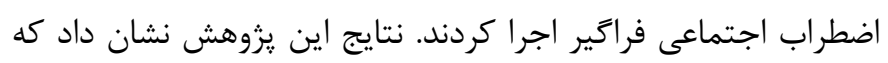
در شرايط آموزش توجهى مثبت در مقايسه با تهديد و كنترل، ميزان إندان

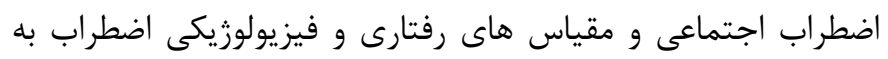

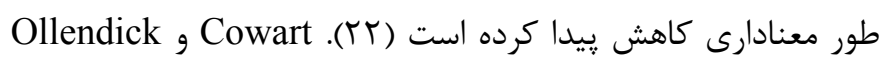

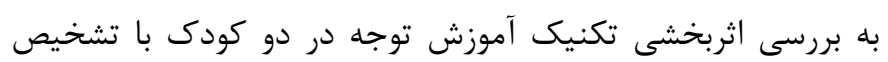

شناختى اضطراب بيان مى دارند كه سوكيرىهاى در يردازش اطلاعات نقش اساسى در علت شناسى و تداوم اختلالات هيجانى بازى مى كنيند

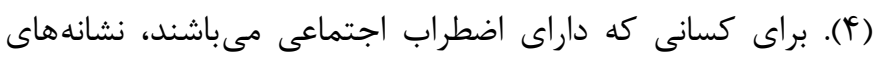

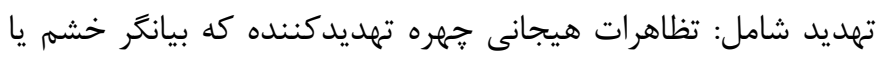
نفرت است و يا كلماتى كه دلالت بر تهلديد اجتماعى دارند (براى مثال

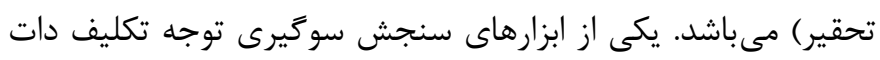

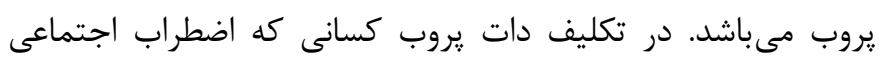

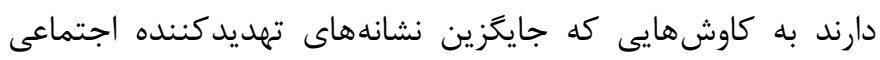

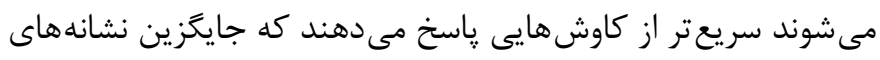

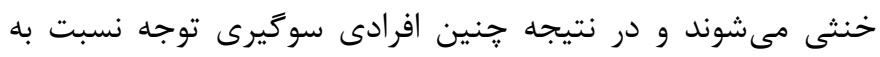

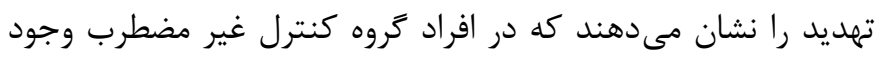

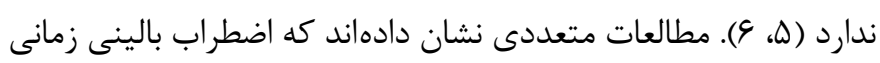

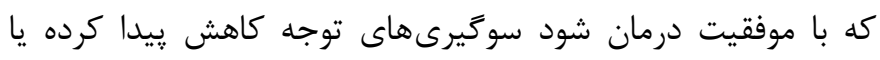

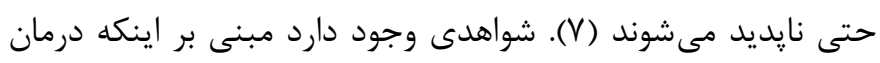

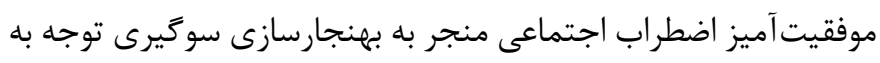

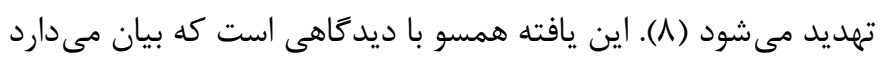

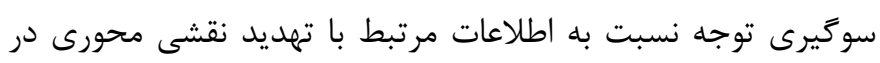

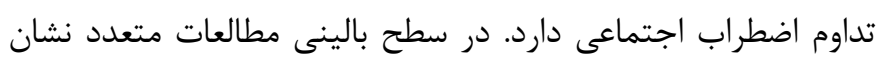

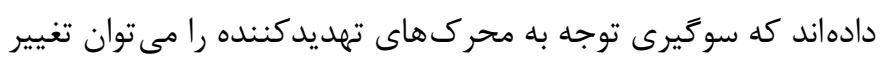

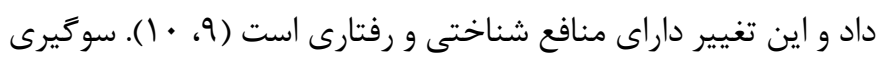

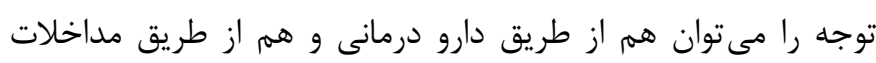

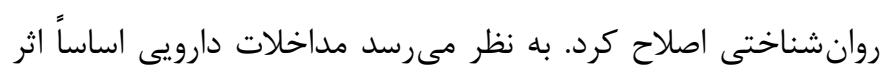

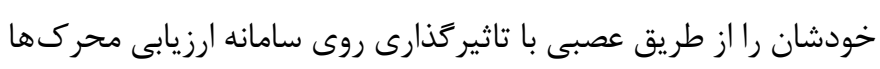

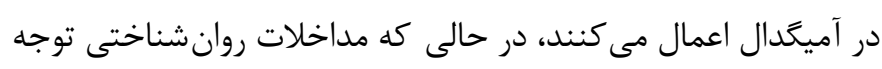

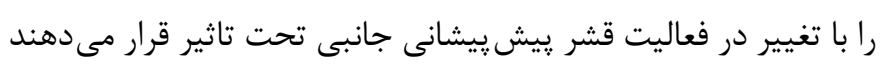

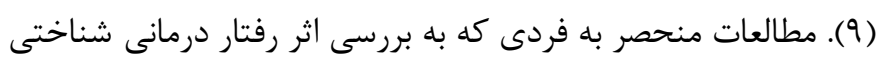
بر روى كاركردهاى (Cognitive behavior therapy (CBT)) توجهى در اختلالات اضطرابى يرداختهاند به اين نتيجه رسيدهاند كه

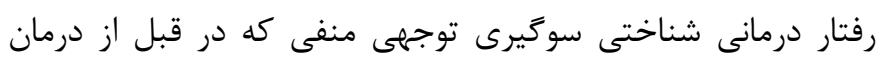

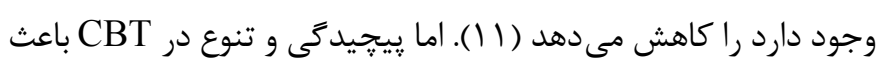

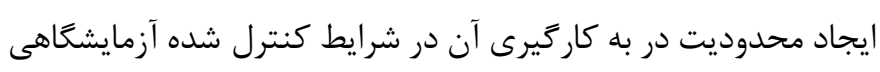

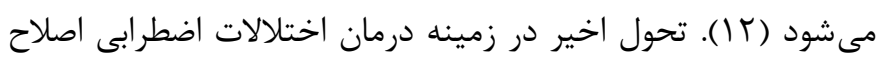
سو ميرى توجه (ABM) (Attention bias modification (ABM) است. ريشه در الكوهاى اخير اضطراب دارد و بر پايه دادههاى آزمايشى (ABM

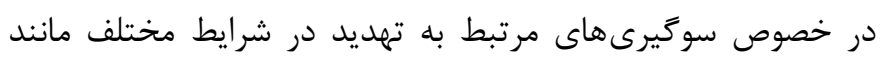

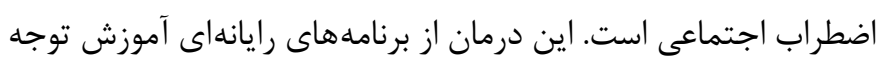

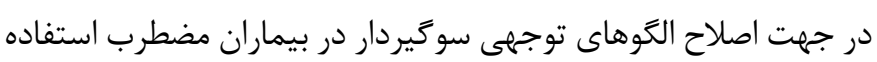


معيارهاى DSM-5 و عدم وجود مشكلات بينايى، مشكلات مغزى،

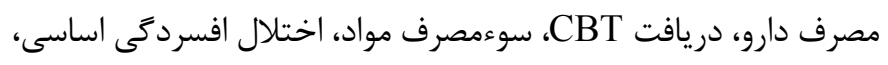

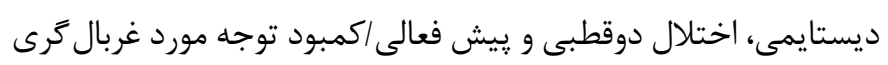

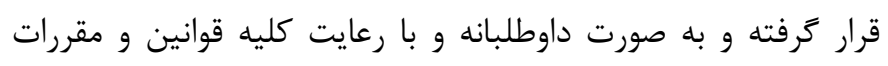

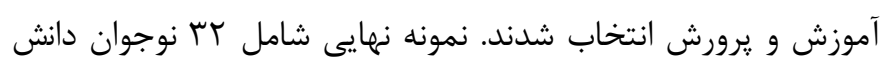

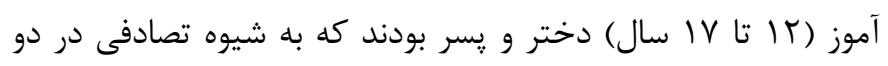

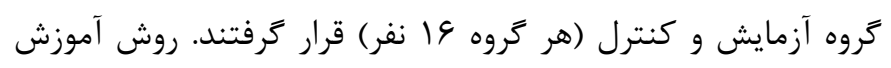

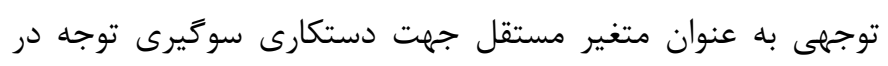

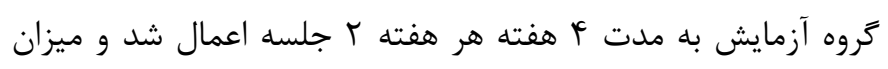

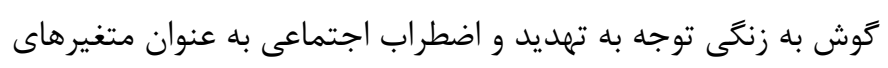

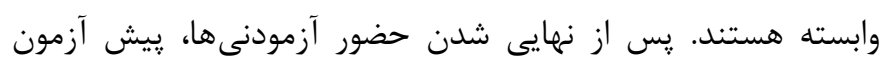

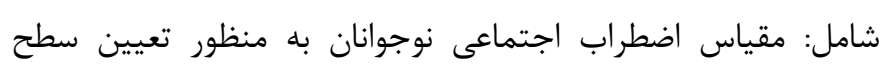

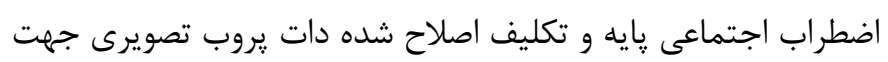

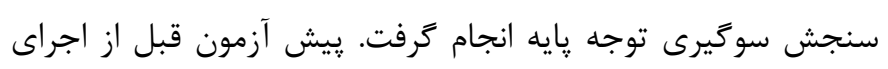

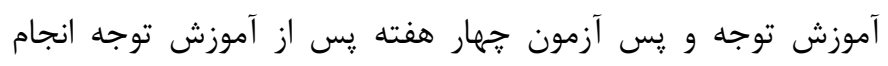

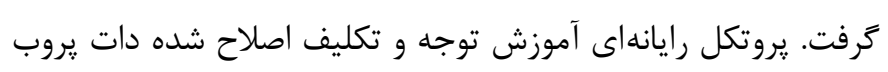

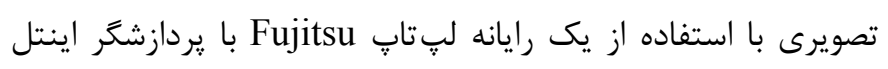

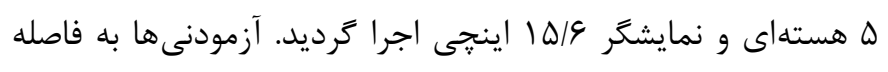

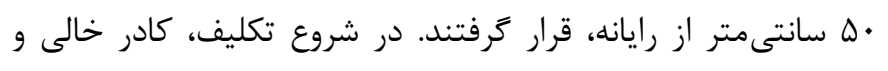

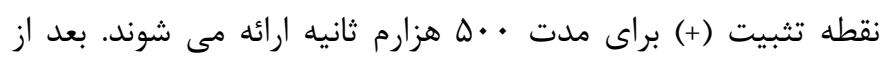

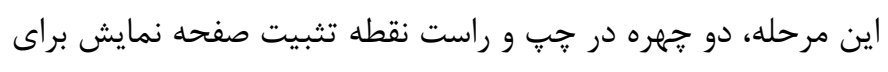

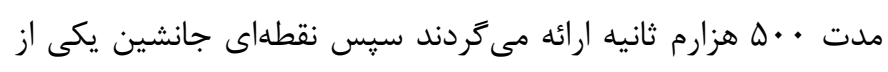

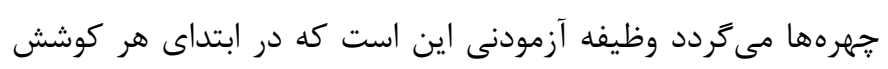

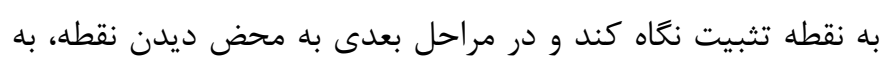

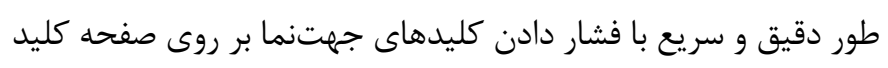

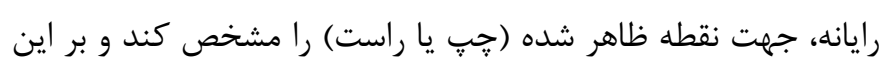

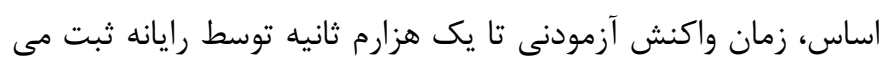

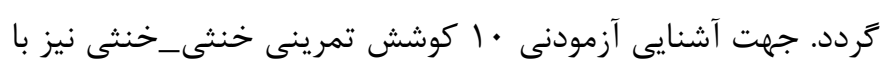

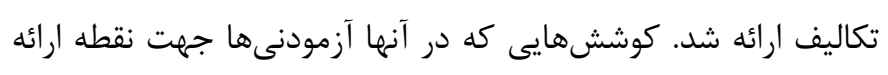

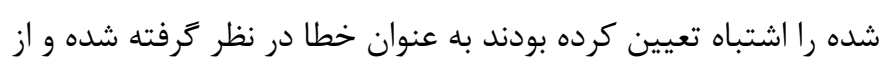
تحليل حذف شدند.

مقياس اضطراب اجتماعى نوجوانان Social anxiety scale)

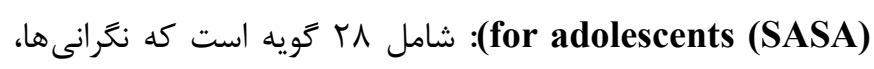

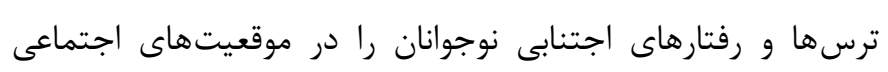

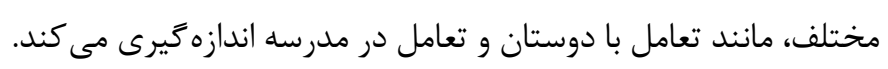

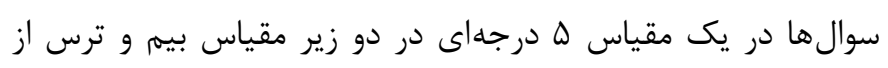

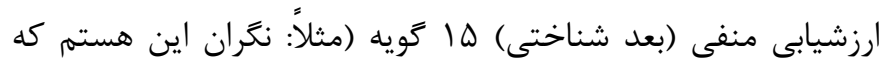

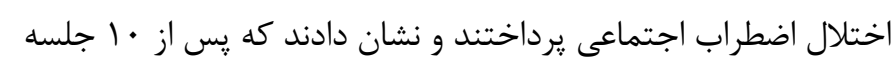

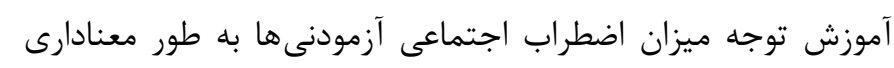

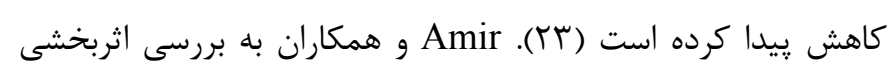

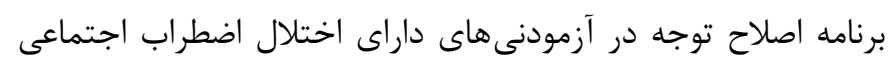

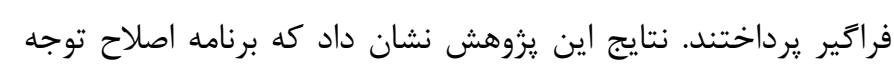

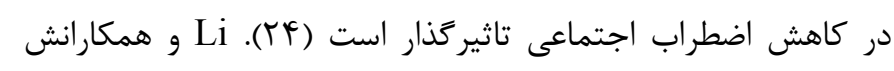

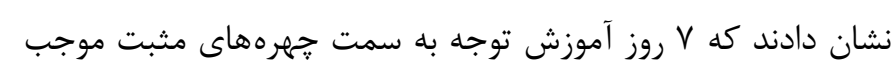

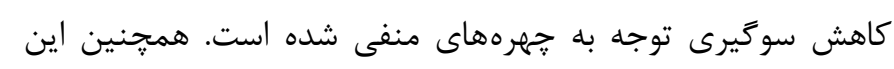

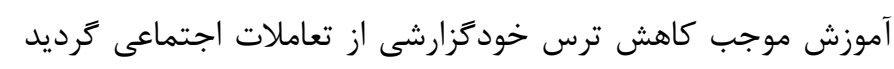

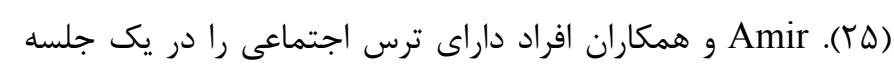

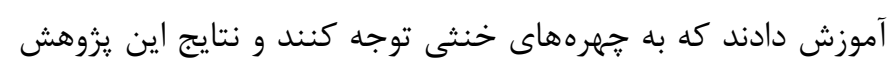

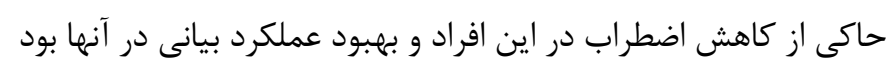

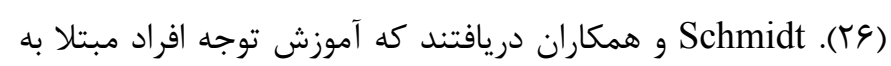

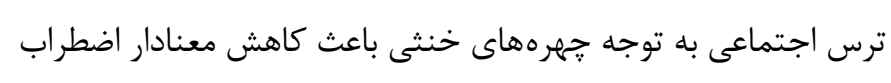

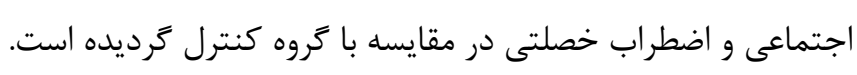

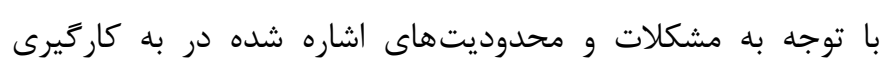
روشهاى درمانى متداول مانند CBT و دارودرمانى براى اختى اختلال

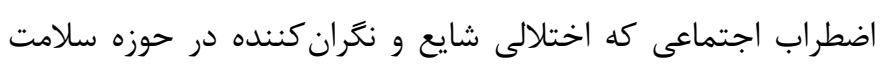

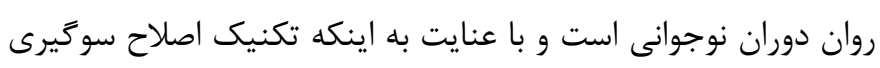

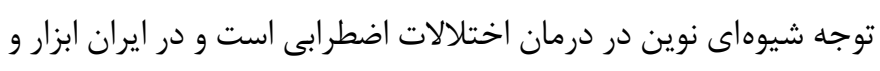
يروهش هاى مشابهى در اين خصوص وجود نداشته و در مقايسه با ادبيات

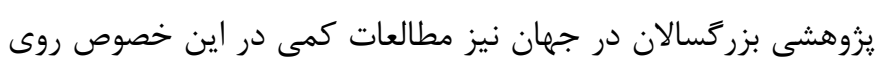

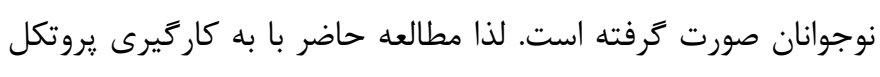

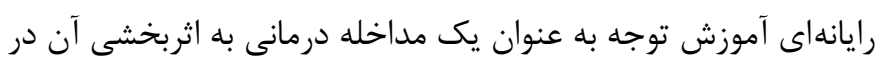
اصلاح سوكيرى توجه و كاهش اضطراب اجتماعى در نوجوانان برداخت.

\section{روش كار}

اين يزوهش جزء تحقيقات كاربردى بود و از روش تجربى با طرح بيش

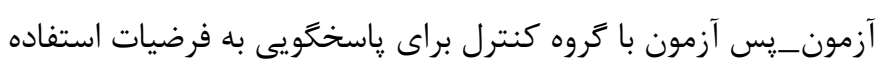

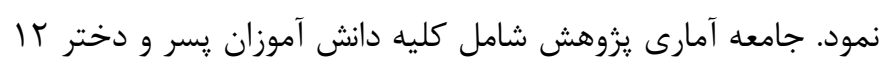

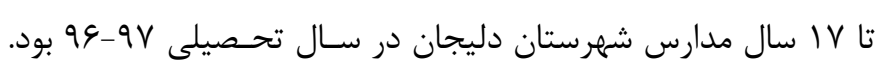

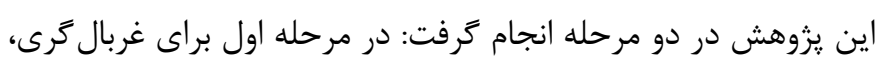

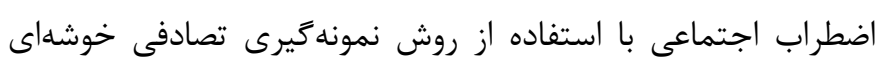

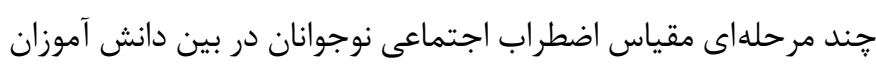

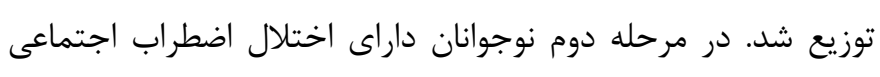

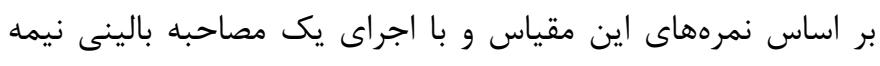

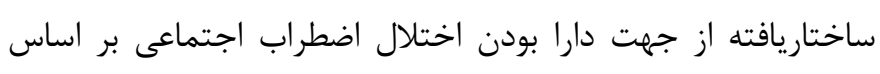


جهره، اين نرم افزار بيش از . ا مولفه جهره از جمله اندازه جشم، دهان يا لب را قابل تغيير مىسازد. اين نرمافزار داراى تواهىنامههاى معتبر

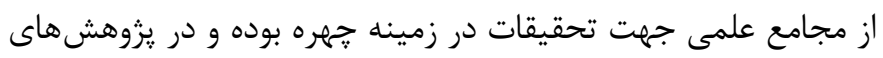

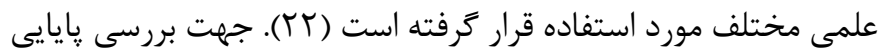

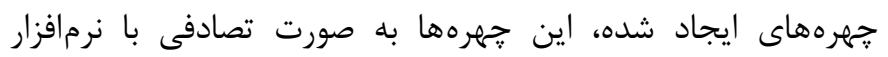

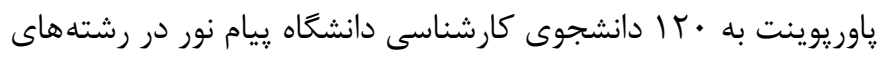

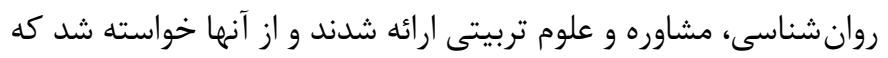
ميزان تهديد كنندكى جهرههاى هيجانى را در يك مقياس ل درجهاى طيف ليكرت از ب- (كاملا منفى) تا ب+ (كاملا مثبت) و صفر (نه مثبت و نه منفى) درجهبندى نمايند. پايايى جهرههاى هاى هيجانى با استفاده

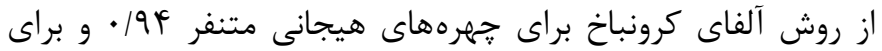
جهرههاى خنىى 9 / • بدست آمد. همجنين بايايى با استفاده از روش

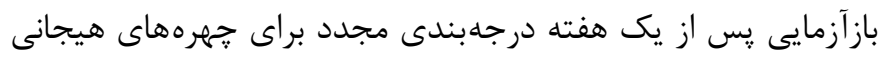

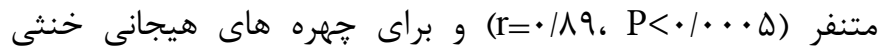

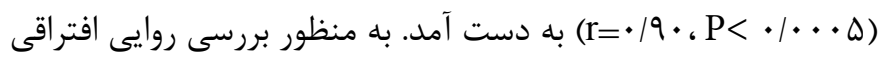
تكليف دات يروب جهرهاى با استفاده از مقياس اضطراب اجتماعى نوجوانان و انجام مصاحبه بالينى نيمه ساختاريافته دو كروه از نوجوانان داراى اضطراب اجتماعى بالا (له نفر) و پايين (ها نفر) از هم ديكر تفكيك شدند و از نظر جنسيت، سن و تحصيلات همتاسازى شدند. سيس تكليف دات يروب קهرهاى بر روى هر دو كروه اجرا شد. مقايسه

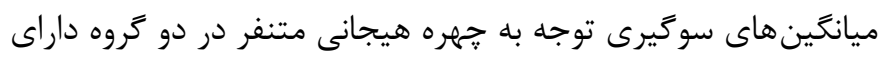
اضطراب اجتماعى بالا و پايين با استفاده از آزمون t مستقل نشان داد لهاد

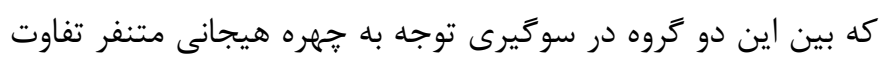

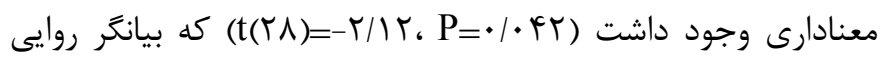
افتراقى تكليف دات يروب جهرهاى در ايجاد تفاوت بين دو گروه بود. هر جلسه تكليف شامل Y Y كوشش بود كه در r ك كوشش آن دو جهره هيجانى خنثى و متنفر به مدت · له هزارم ثانيه ارائه مىشد و اهداف (نقطه) به صورت مساوى در موقعيت جهره هيجانى خنثى و متنفر قرار مى كرفت. در 19 كوشش باقى مانده نيز دو جهره هيجانى خنثى ارائه مى شد.

\section{Computerized attention- برنامه رايانهاى آموزش توجد} training program سوكيرىهاى توجهى را در دو جهت (به سمت و دور از تهديد) مهيا مى كنند. در آموزش توجه از تكليف اصلاح شده دات يروب استفاده دواه مىشود كه در آن موقعيت هدف به صورت نظامدارى به منظور افزايش ميزان آشكار شدن اهداف در موقعيت مورد نظر آموزش سوكيرى دستكارى مىشود. در اين يزوهش برنامه آموزش توجه به مدت ع
همسالان مرا دوست نداشته باشند) و در زير مقياس تنش و بازدارى در برخورد اجتماعى (بعد رفتارى) سا گَويه (مثلاً: در كروه همسالان

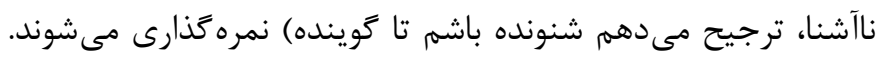
زيرمقياس بيم و ترس از ارزشيابى منفى ترسها، نكرانى ها و انتظار

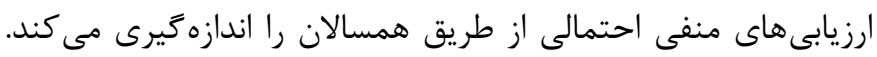

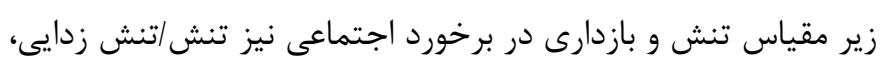

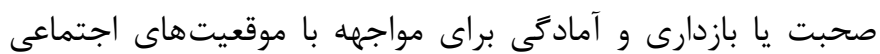

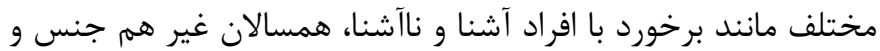
شركت در بحث هاى كلاسى را اندازهگيرى مى كند. همسانى درونى اين زير مقياسها در مطالعات مختلف تاييد شده است (YY). نتايج تحليل عاملى خدايى و همكاران با هدف بررسى روايى عاملى SASA نشان

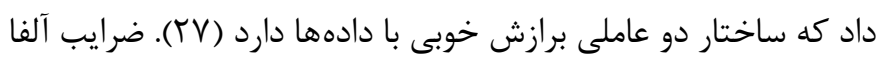
براى زير مقياسهاى بيم و ترس از ارزيابى منفى و تنش و بازدارى در براحس

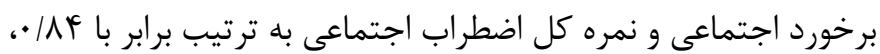

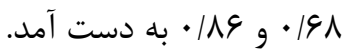

\section{تكليف اصلاح شده دات بروب تصويرى Pictorial version} of Modified Dot-probe Task تكليف اصلى است كه توسط MacLeod و همكاران براى بررسى انتقال توجه بينايى و سنجش سوكيرى توجه بر اساس الكوى روانشناسى

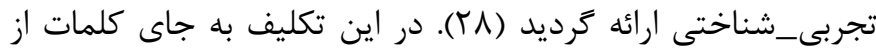
جهرههاى هيجانى متنفر و خنثى استفاده شد. به كار كيرى جهره متنفر به دلايل متعددى صورت كرفت. ابتدا اينكه شواهد علمى وجود دارد

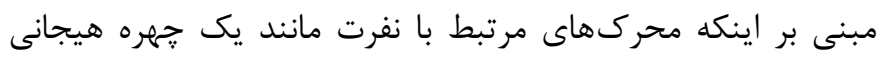

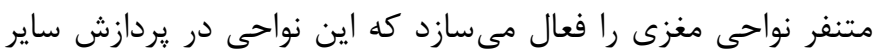
محرك هاى هيجانى مانند ترس نيز نقش دارند (9 (؟). جهره متنفر منتقل كننده يِيام بيزارى و طرد شدن است كه نكرانى اصلى افراد داراى اضطراب اجتماعى است و نسبت به ساير هيجانها، افراد داراى اضطراب

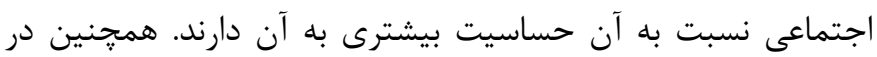

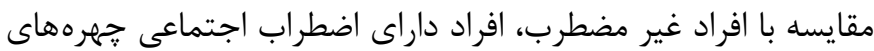
متنفر را در مقايسه با جهرههاى هيجانى خشمخين، منفى تر درجهبندى

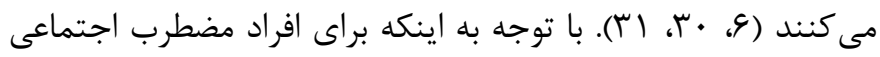

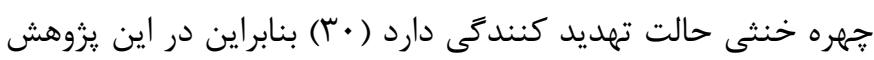

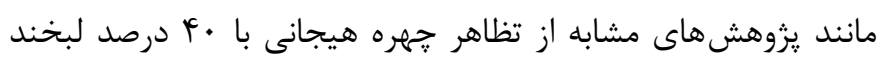

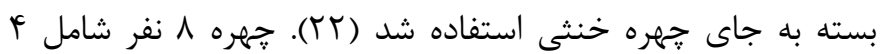

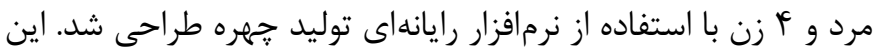

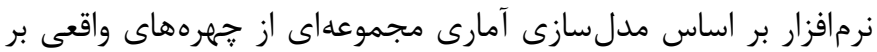
مبناى تنوع قوميتى، سنى و جنسيتى طراحى شده است. براى الكوسازى 
مثبت نشان دهنده كوش بزنكى توجهى نسبت به جهره هيجانى و نمره منفى نشان دهنده اجتناب توجهى از جهره هيجانى است. به منظور بررسى اثربخشى آموزش توجه بر سو متنفر در نوجوانان داراى اضطراب اجتماعى بالا، از تحليل واريانس

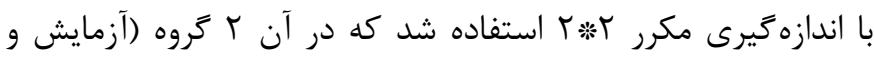

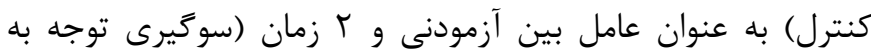
جهرههاى هيجانى متنفر: يِيش آزمون_يس آزمون) به عنوان عامل

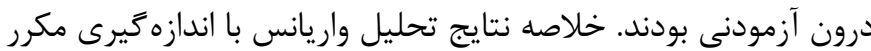
در جدول هاى ا و Y ارايه شده است. نتايج نشان داد كه اثر اصلى زمان

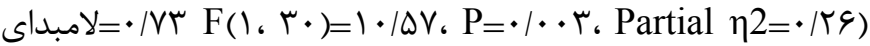

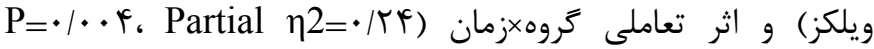

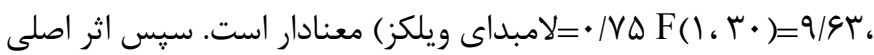
معنادار بر اساس اثر تعاملى مورد تحليل قرار كرفت.

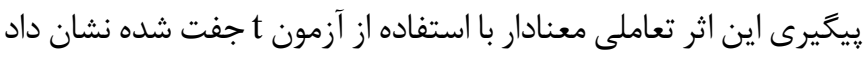

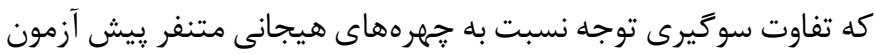

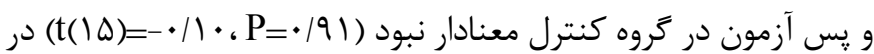
حالى كه در كروه آزمايش تفاوت سوگيرى توجه نسبت به جهره تهاى

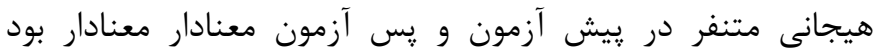
. $(\mathrm{t}(\mid \Delta)=-\mathcal{F} / \mathcal{F} \Delta, \mathrm{P}<\cdot / \cdots \Delta)$ نتايج اين تحليل بيانكر آن است كه به كاركيرى تكنيك آموزش توجه در گروه آزمايش موجب تغيير سوكيرى توجه نسبت به جهره
هفته هر هفته Y جلسه آموزش كه در مجموع شامل ^ جلسه آموزش توجه بود كه به منظور القاى سوكيرى توجه اجتناب از تهديد (جهره هيجانى متنفر) در كروه آزمايشى نوجوانان مضطرب اجتماعى اجرا شد.

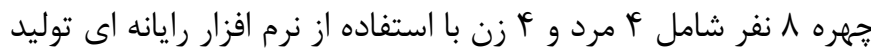

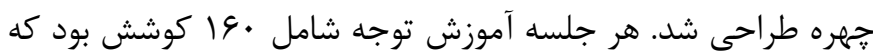

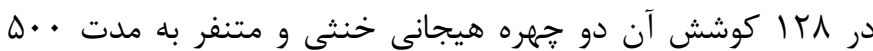
هزارم ثانيه ارائه شد و اهداف (نقطه) با فراوانى بيشترى در هو در درصد

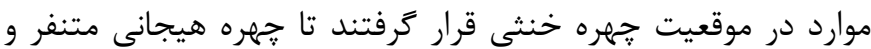
در بr كوشش باقى مانده نيز دو جهره هيجانى خنثى ارائه شد. فرض

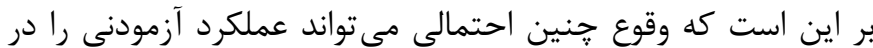
تكليف آسان كند و به صورت ضمنى آزمودنى سوكيرى اجتناب از ازئ

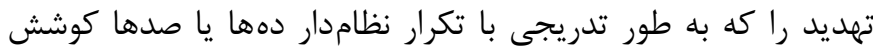

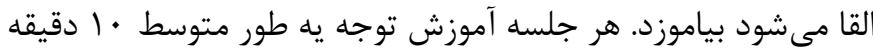

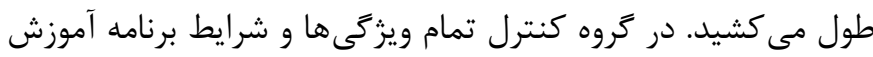
توجه وجود داشت، به جز اينكه احتمال وقوع نقطه در حالت جهره خنثى_متنفر برابر است.

\section{بافته ها}

نمره سوكيرى توجه نسبت به جهرههاى هيجانى از طريق كم كردن زمان واكنش آزمودنى در حالتى كه نقطه همايند با جهره بود از زمانه واكنش حالتى كه نقطه ناهمايند با جهره بود محاسبه كرديد. نمره

جدول 1. ميانكَين و انحراف معيار نمره سوكيرى توجه به جهره هيجانى متنفر در پيش ويس آزمون كروه آزمايش و كنترل

\begin{tabular}{|c|c|c|c|c|c|}
\hline \multicolumn{2}{|c|}{ انحراف معيار } & \multicolumn{2}{|c|}{ ميانگين } & \multirow{2}{*}{ تعداد } & \multirow{2}{*}{ كروه } \\
\hline يس ازمون & ييش آزمون & يس ازمون & ييش آزمون & & \\
\hline $1 / 19 \Delta$ & $r \cdot \mid q 4$ & $\mid Q / F \Delta$ & $-r \mid / r q$ & 19 & آزمايش \\
\hline $18 / v 9$ & TH/AF & |r/|| & $-1 \% / 9 V$ & 19 & كنترل \\
\hline
\end{tabular}

جدول ז. خلاصه نتايج تحليل واريانس با اندازميرى مكرر براى (ييش آزمون و پِ آزمون سوكيرى توجه به جهره هيجانى متنفر)

\begin{tabular}{|c|c|c|c|c|c|c|}
\hline مجذو ر اتا & $\mathbf{P}$ & $\mathbf{F}$ & درجه آزادى & مجذذوراتين & مجذورات & منبع واريانس \\
\hline . & $\cdot / \cdot r$ & $1 \cdot 1 \Delta V$ & 1 & $\Delta S \wedge V / T G$ & $\Delta S \wedge V / T G$ & زمان \\
\hline \multirow[t]{2}{*}{$\cdot / T^{k}$} & $\cdot \cdot \cdot r$ & $9 / 94$ & 1 & $\Delta 111 / 4 q$ & $\Delta 111 / 4 q$ & تروه× زمان \\
\hline & - & - & $r$. & $\Delta r \Lambda / \cdot$ & $|\varepsilon| f \cdot / \cdot q$ & خطا (زمان) \\
\hline
\end{tabular}




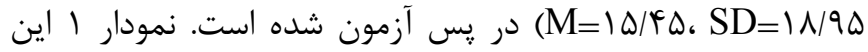

هيجانى متنفر در نوجوانان داراى اضطراب اجتماعى از حالت اجتنابى نتايج را نشان مىدهد.

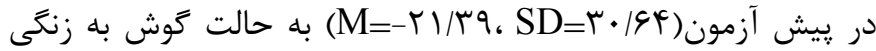

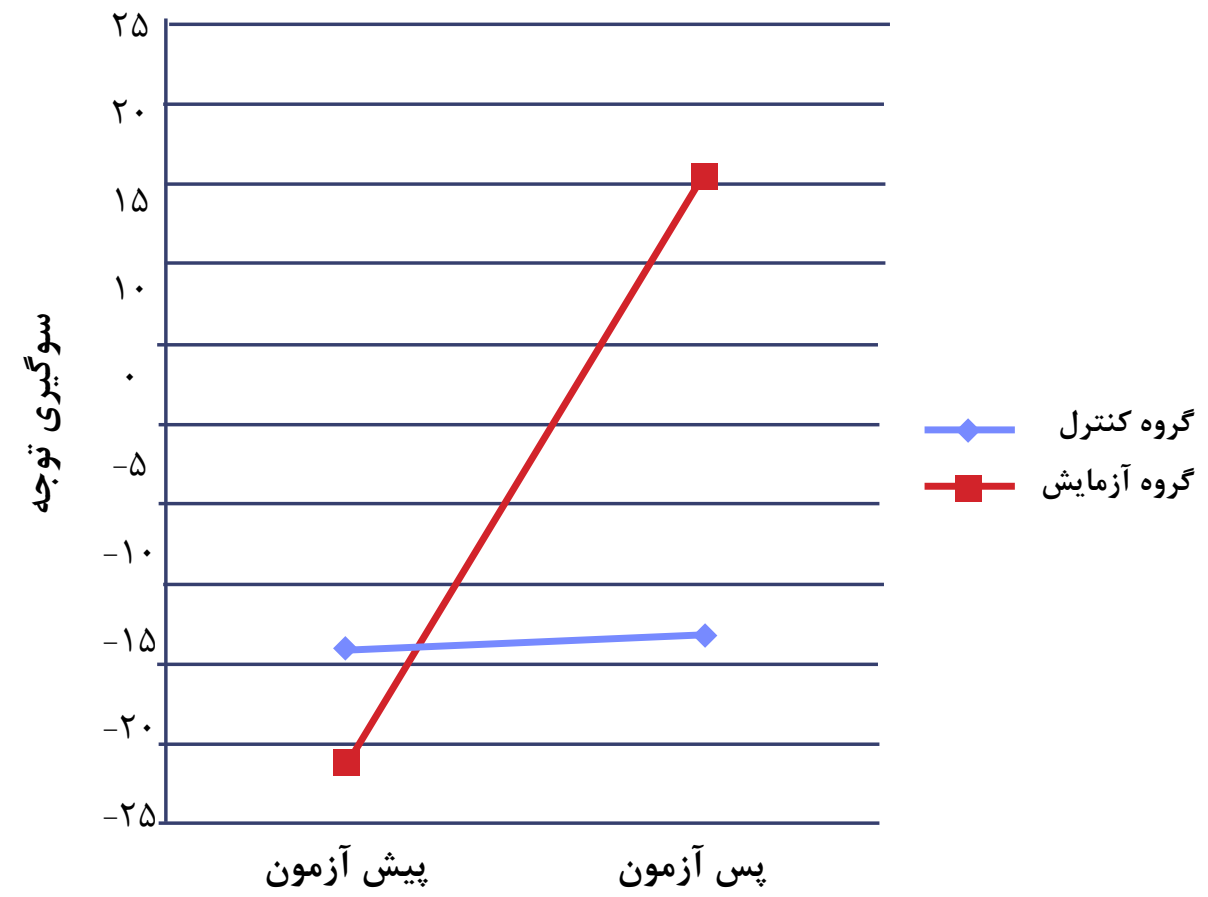

نمودار ا. نمرات يِيش آزمون و يِ آزمون سوَيرى توجه به جهرههاى هيجانى متنفر دركروه آزمايش و كنترل

به منظور بررسى اثربخشى آموزش توجه در كاهش ميزان اضطراب اجتماعى آزمودنى و r زمان (اضطراب اجتماعى: يِيش آزمون_يس آزمون) به عنوان

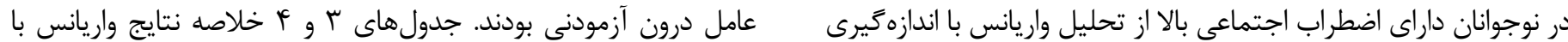

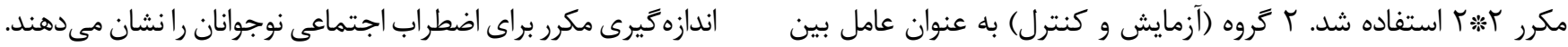
جدول r. ميانكَين و انحراف استاندارد اضطراب اجتماعى پيش و پِ آزمون در دو كروه آزمايش و كنترل

\begin{tabular}{|c|c|c|c|c|c|}
\hline \multicolumn{2}{|c|}{ انحراف معيار } & \multicolumn{2}{|c|}{ ميانغين } & \multirow{2}{*}{ تعداد } & \multirow{2}{*}{ كروه } \\
\hline يس ازمون & ييش آزمون & يس ازمون & ييش آزمون & & \\
\hline IT/TT & $V / \Delta \Lambda$ & $Q T / F T$ & $1 . g / F F$ & 19 & زمايش \\
\hline $11 / \Delta \Lambda$ & $9 / 10$ & $1.1 / 94$ & $1.4 / 99$ & 19 & كنترل \\
\hline
\end{tabular}

جدول أ. خلاصه نتايج تحليل واريانس با اندازمكيرى مكرر براى كروه×زمان (اضطراب اجتماعى: ييش آزمون و پِ آزمون)

\begin{tabular}{|c|c|c|c|c|c|c|}
\hline مجذو ر اتا & $\mathbf{P}$ & $\mathbf{F}$ & درجه آزادى & مجذذوراتين & مجذورات & منبع واريانس \\
\hline . Mt & $\cdot 1 \cdot \cdots 1$ & $r 1 / 90$ & 1 & $|1 \& F / D|$ & $|194 / D|$ & زمان \\
\hline . & $\cdot / \cdot \Delta$ & $q / \cdot r$ & 1 & EVN/DI & EVN/DI & كروه× زمان \\
\hline & - & - & r. & $\Delta r / \cdot f$ & $\mid \Delta 91 / 4 q$ & خطا (زمان) \\
\hline
\end{tabular}


آزمون و يس آزمون در كروه كنترل معنادار نبود (

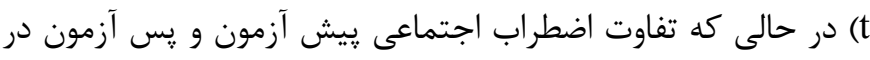

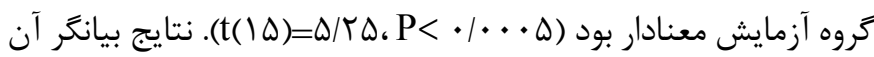

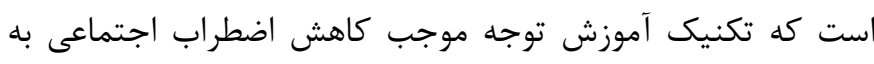

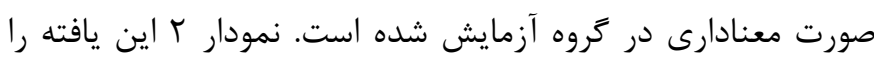
نشان مى دهد.

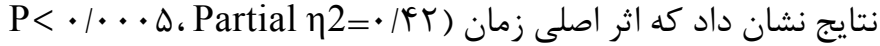

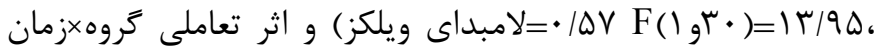
(

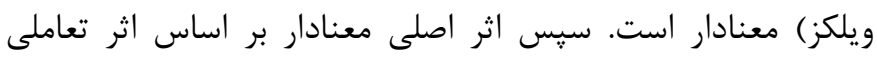

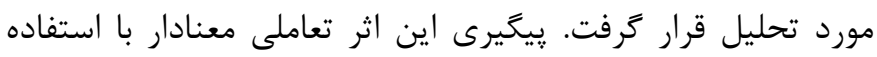

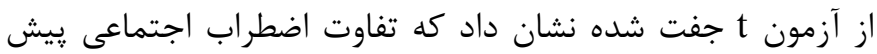

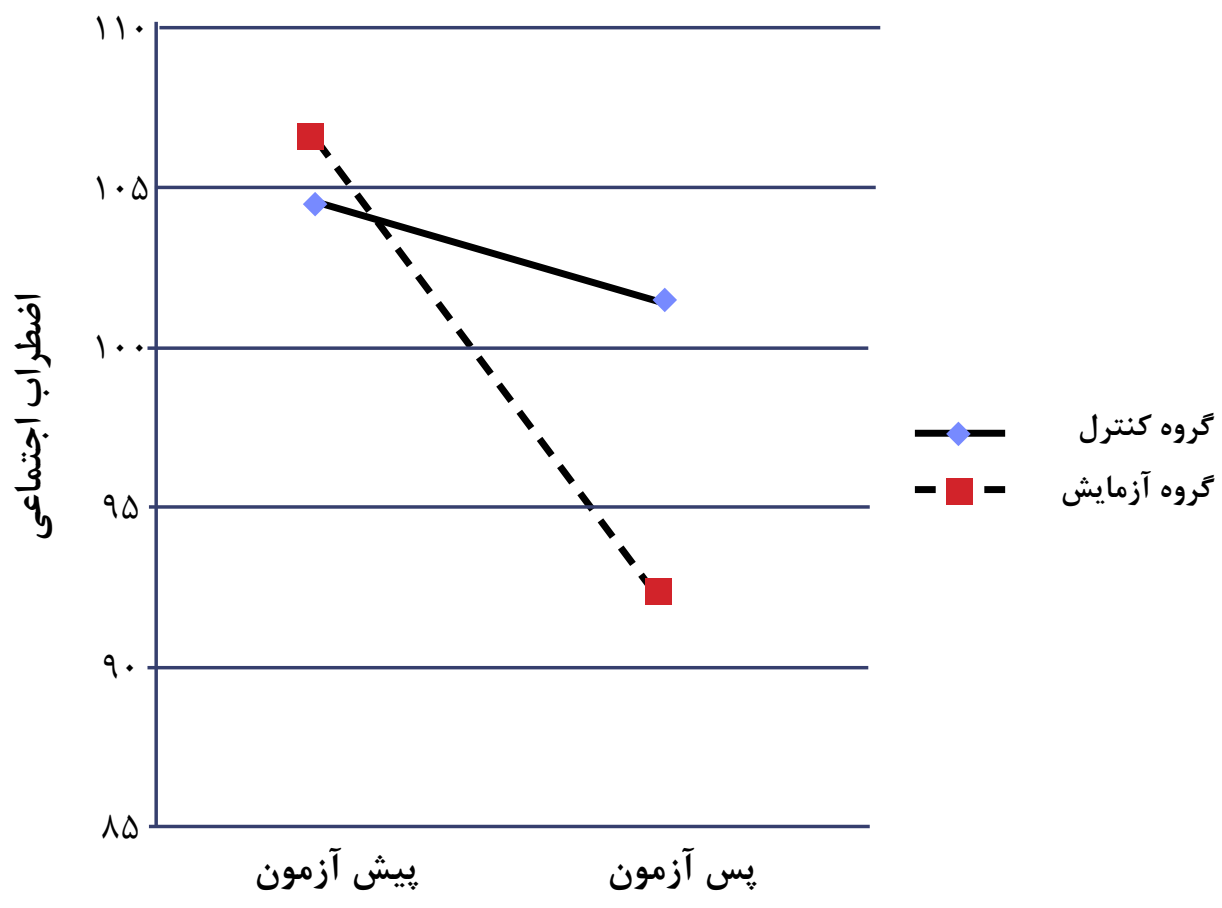

نمودار ك. اضطراب اجتماعى بِيش آزمون و پس آزمون در كروه آزمايش و كنترل

سو كيرى توجه به تهديد و كاهش يا حتى نايديد شدن آن مىشود (V)

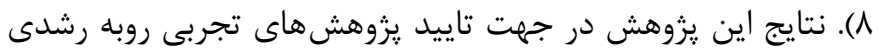
است كه كارآمدى فرايندهاى آموزش توجه رايانهاى را در كاهش علائم ترون

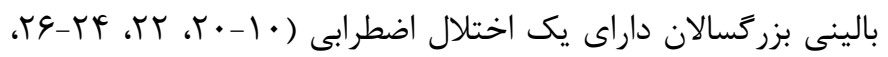

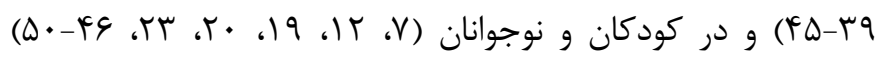

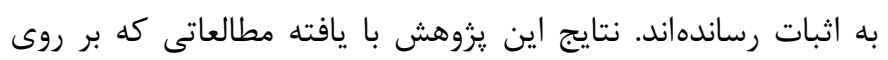

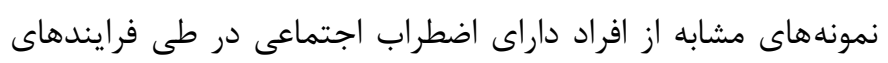

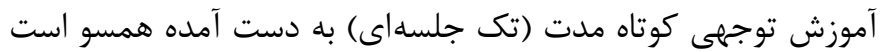

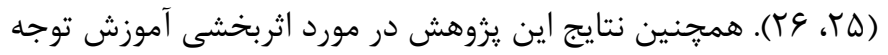
در كاهش اضطرب اجتماعى نوجوانان با يافته هاى فيزيولوزيكى به دست

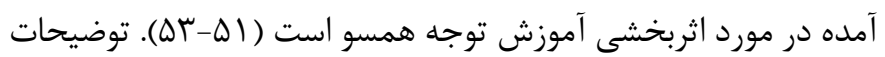

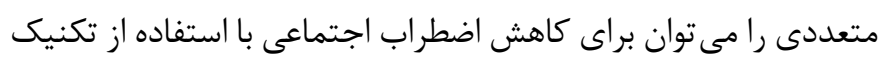

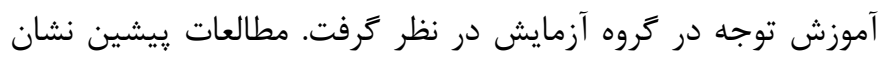

نتايج اين يزوهش نشان داد كه در گروه آزمايش، آموزش توجه موجب تغيير در سوكيرى توجه به محرك تهديدكننده جهره هيجانى متنفر از

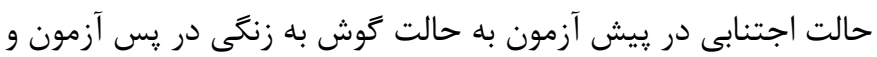

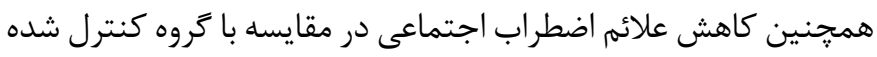

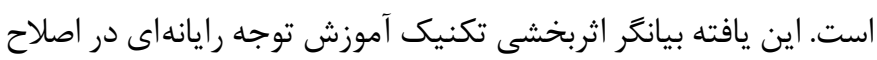

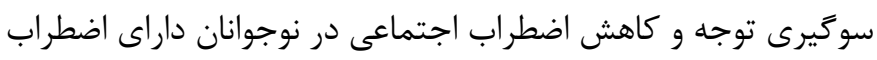

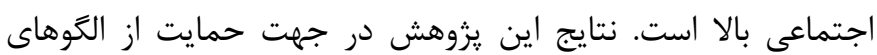

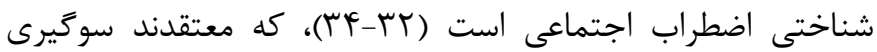
توجه به اطلاعات تهديدكننده اجتماعى تاثير عليتى در تداوم اضطراب اجتماعى دارد. اين يافته همسو با نتايج يروهشهايى است كه فرضيه

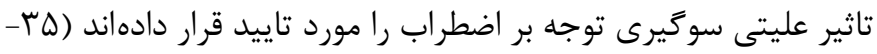

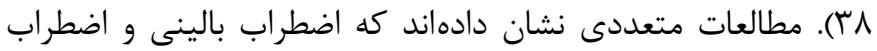

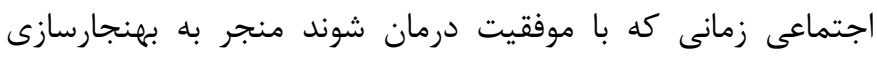


كروه آزمايش موجب شد كه آزمودنى ها موقعيتهاى اجتماعى بيرونى را كمتر تهديد كننده بدانند و كاهش ارزيابى تهديد منجر به رفتارهاى اجتنابى كمتر شد، براى اين گروه آموزش توجه فرصت و مجال بيشترى

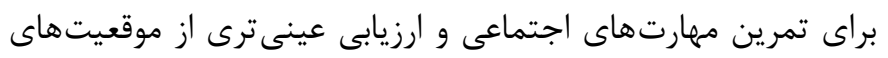

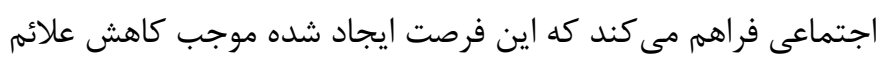

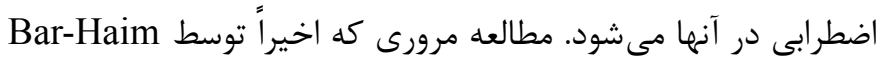

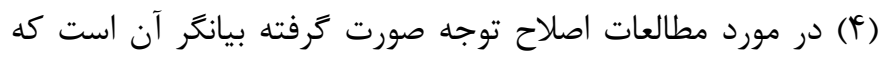
برنامهاى آموزش توجه، سوگيرىهاى توجهى مرتبط با ارزشهای

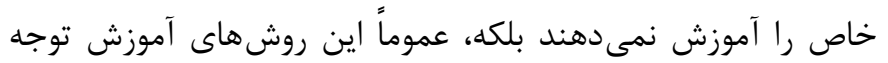

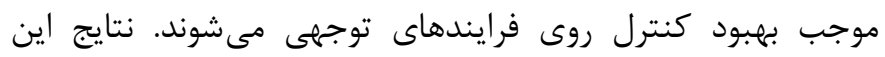

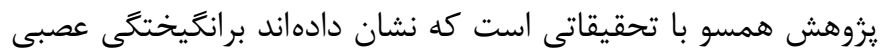

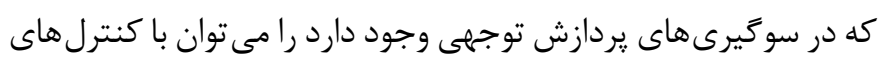

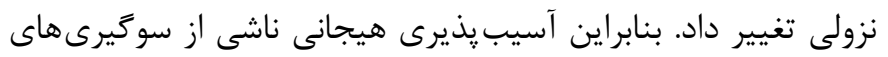

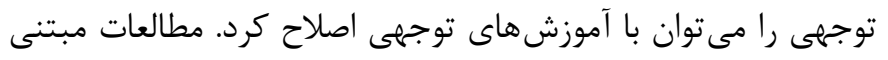

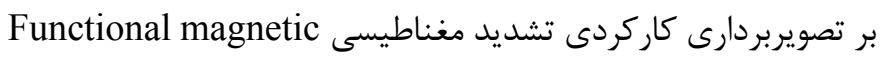
نيز از اين موضوع حمايت كردهاند مesesonance imaging (FMRI) ( •). بنابراين در مجموع به نظر مىرسد اصلاح سوكيرى توجه باعث بهبود كنترل توجهى مىشود تا اينكه مولفههاى محرك_مدار (صعودى) سوكيرى توجه به تهديد را مد نظر قرار دهد. در حمايت از

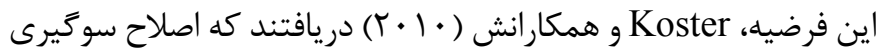
توجه مراحل آخر (·•l1 هزارم ثانيه) يردازش تهديد را تحت تاثير

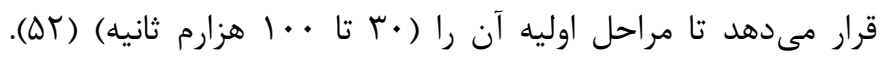

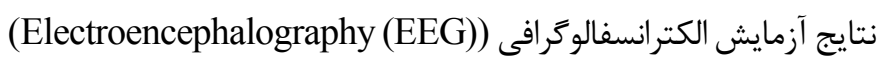

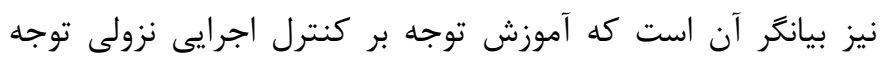

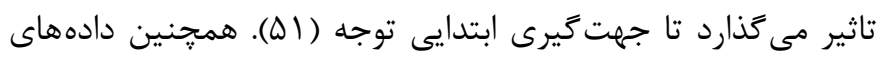

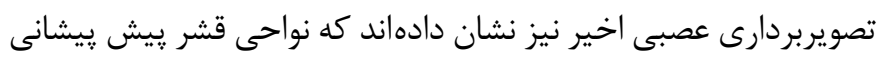
در اصلاح سوكيرى توجه ميانجى گرى مى كنند كه مويد يردازش كنترل

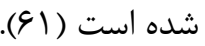

\section{نتيجه گَيرى}

آموزش توجه يا اصلاح سوكيرى توجه را مى توان به صورت مستقل

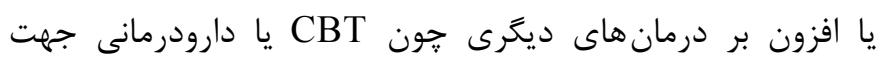

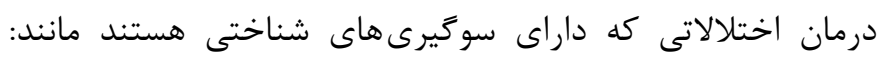

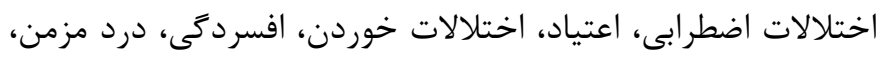

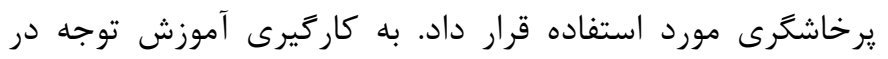
بازتوانى اختلالات نوروسايكولوزيكى نيز بيانكر اثربخشى اين تكنيك

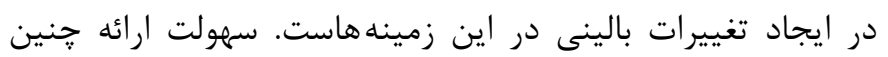

دادهاند كه افراد داراى اضطراب اجتماعى ترجيحاً اطلاعات اجتماعى منفى را يردازش مى كنند (DF). ناتوانى در بازگيرى توجه از تهديد

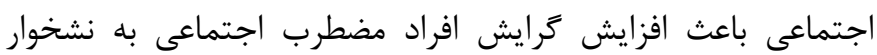

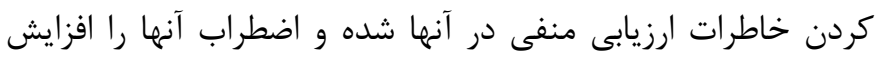

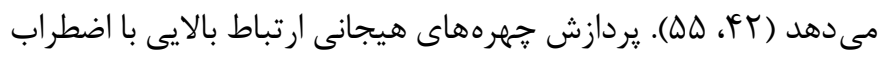

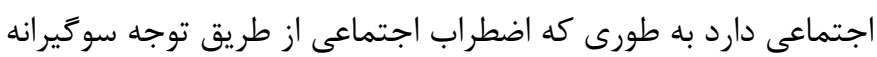

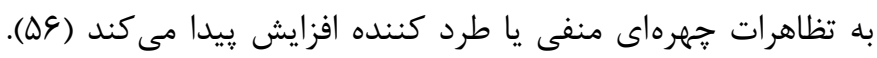
اگر افراد داراى اضطراب اجتماعى توجهشان را به سمت اطلاعات منفى جهت گيرى كنند و اين سوكيرى توجه به صورت على در تداوم اضطراب نقش داشته باشد، بنابراين هركونه فرايندى كه بتواند جنين

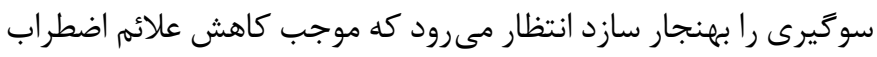

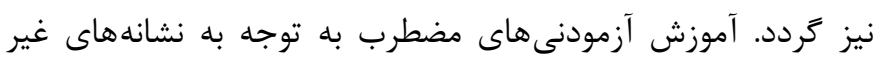
تهديدكننده خرخه معيوب شكل كرفته بين اضطراب و سوكيرى توجه إنه

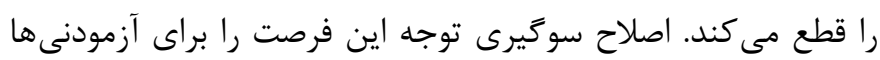

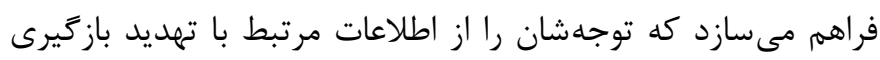

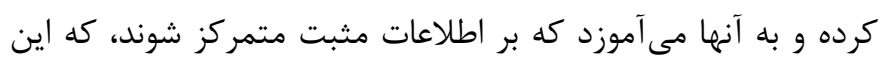

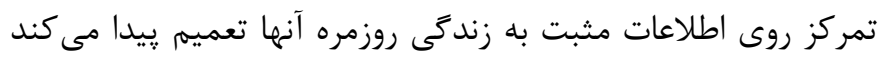
و تجارب اجتماعى مثبتى را خواهند داشت. آموزش توجه نكرش آنه آنها را نسبت به تجارب اجتماعى قبلى تغيير داده و موجب كاهش ترس

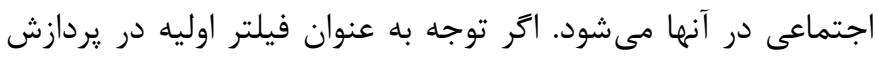

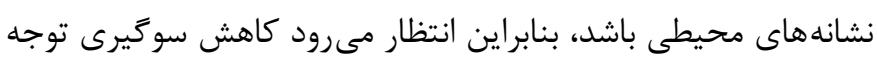

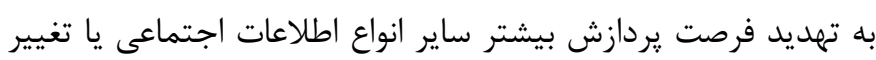

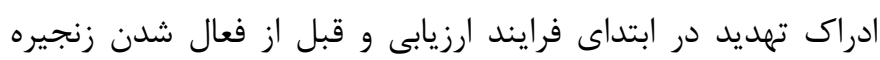

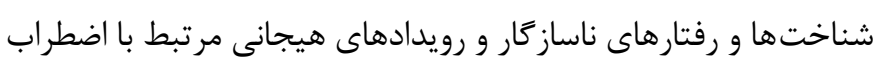

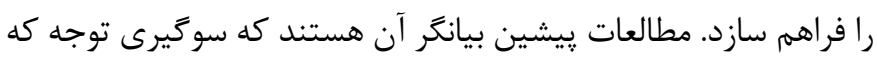
از ويزگى افراد مضطرب است توسط تفاوتهاى فردى در كنترل توجهى تعديد مىشود، به طورى كه آزمودنى هاى مضطربى كه كنترل توجهى ضعيفى دارند در باز گيرى توجهى از نشانه هاى تهديد بسيار كند هستند

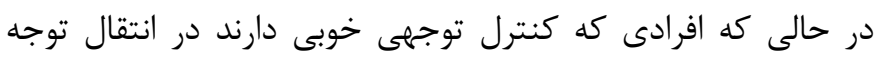

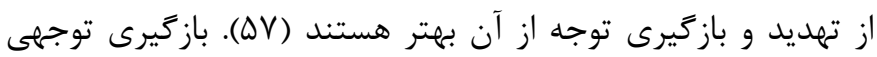

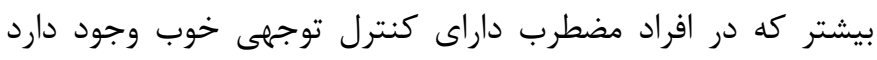

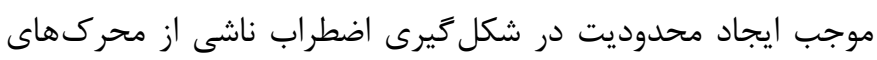

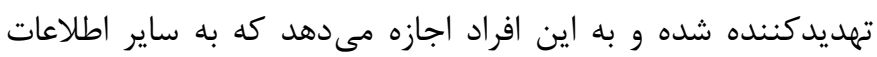

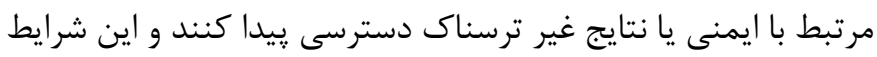
كنار آمدن موثرترى را براى فرد ايجاد مى كند. در حقيقت شواهدى بادي علمى وجود دارد مبنى بر اينكه كنترل توجهى خوب عاملى محافظت

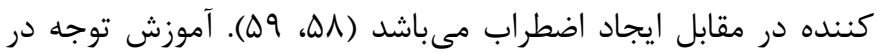


نداشته يا جنين درمان هايى را انتخاب نمى كنند.

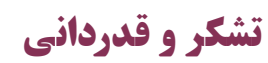

اين تحقيق با استفاده از اعتبارات يزوهشى دانشگاه ييام نور انجام شده است و از كليه كسانى كه در اجراى اين تحقيق با ما همكارى نمودند كمال سياس گزارى و تشكر را داريم.

\section{References}

1. Rheingold AA, Herbert JD, Franklin ME. Cognitive bias in adolescents with social anxiety disorder. Cognitive Therapy and Research. 2003;27(6):639-655.

2. Beidel DC, Turner S. Child Anxiety Disorders: A guide to research and treatment. Abingdon:Routledge;2007.

3. Geravand F, Afzali MH, Shokri O, Parsian M, Puklek M, Khodaei A, et al. Gender and age differences in social anxiety in adolescence. Developmental Psychology: Iranian Psychologists. 2011;7(26):165-174. (Persian)

4. Bar-Haim Y. Research review: attention bias modification (ABM): A novel treatment for anxiety disorders. Journal of Child Psychology and Psychiatry. 2010;51(8):859-870.

5. Mogg K, Philippot P, Bradley BP. Selective attention to angry faces in clinical social phobia. Journal of Abnormal Psychology. 2004;113(1):160-165.

6. Pishyar R, Harris LM, Menzies RG. Attentional bias for words and faces in social anxiety. Anxiety, Stress \& Coping. 2004;17(1):23-36.

7. Eldar S, Ricon T, Bar-Haim Y. Plasticity in attention: Implications for stress response in children. Behaviour Research and Therapy. 2008;46(4):450-461.

8. Carlbring P, Apelstrand M, Sehlin H, Amir N, Rousseau A, Hofmann SG, et al. Internet-delivered attention bias modification training in individuals with social anxiety disorder-a double blind randomized controlled trial. BMC Psychiatry. 2012;12(1):66.

9. Browning M, Holmes EA, Harmer CJ. The modification of attentional bias to emotional information: A review of the

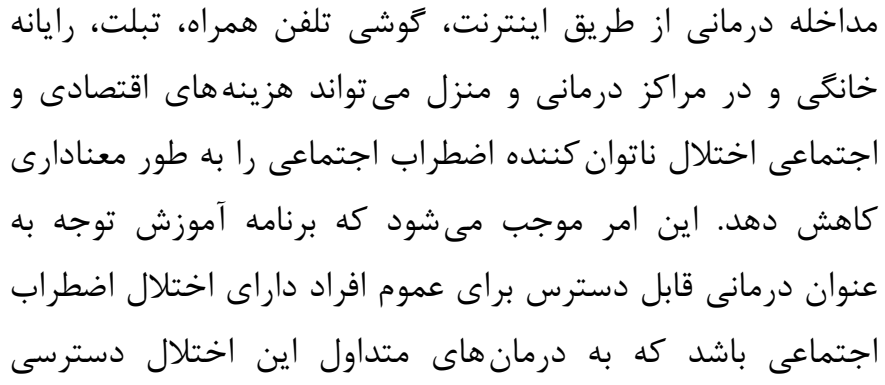

techniques, mechanisms, and relevance to emotional dis orders. Cognitive, Affective, \& Behavioral Neuroscience. 2010;10(1):8-20.

10. Hakamata Y, Lissek S, Bar-Haim Y, Britton JC, Fox NA, Leibenluft E, et al. Attention bias modification treatment: a meta-analysis toward the establishment of novel treatment for anxiety. Biological Psychiatry. 2010;68(11):982-290.

11. Mathews A, Mogg K, Kentish J, Eysenck M. Effect of psychological treatment on cognitive bias in generalized anxiety disorder. Behaviour Research and Therapy. 1995;33(3):293303.

12. Rozenman M, Weersing VR, Amir N. A case series of attention modification in clinically anxious youths. Behaviour Research and Therapy. 2011;49(5):324-430.

13. MacLeod C, Koster EH, Fox E. Whither cognitive bias modification research? Commentary on the special section articles. Journal of Abnormal Psychology. 2009;118(1):89-99.

14. Amir N, Beard C, Taylor CT, Klumpp H, Elias J, Burns M, et al. Attention training in individuals with generalized social phobia: A randomized controlled trial. Journal of Consulting and Clinical Psychology. 2009;77(5):961-973.

15. Amir N, Beard C, Burns M, Bomyea J. Attention modification program in individuals with generalized anxiety disorder. Journal of Abnormal Psychology. 2009;118(1):28-33.

16. Dandeneau SD, Baldwin MW, Baccus JR, Sakellaropoulo M, Pruessner JC. Cutting stress off at the pass: Reducing vigilance and responsiveness to social threat by manipulating attention. Journal of Personality and Social Psychology. 
2007;93(4):651-666.

17. Hazen RA, Vasey MW, Schmidt NB. Attentional retraining: A randomized clinical trial for pathological worry. Journal of Psychiatric Research. 2009;43(6):627-633.

18. Schmidt NB, Richey JA, Buckner JD, Timpano KR. Attention training for generalized social anxiety disorder. Journal of Abnormal Psychology. 2009;118(1):5-14.

19. De Voogd EL, Wiers RW, Prins PJ, Salemink E. Visual search attentional bias modification reduced social phobia in adolescents. Journal of Behavior Therapy and Experimental Psychiatry. 2014;45(2):252-259.

20. Sportel BE, de Hullu E, de Jong PJ, Nauta MH. Cognitive bias modification versus CBT in reducing adolescent social anxiety: A randomized controlled trial. PLoS One. 2013;8(5):e64355.

21. Boettcher J, Leek L, Matson L, Holmes EA, Browning M, MacLeod C, et al. Internet-based attention bias modification for social anxiety: a randomised controlled comparison of training towards negative and training towards positive cues. PloS One. 2013;8(9):e71760.

22. Heeren A, Reese HE, McNally RJ, Philippot P. Attention training toward and away from threat in social phobia: Effects on subjective, behavioral, and physiological measures of anxiety. Behaviour Research and Therapy. 2012;50(1):30-39.

23. Cowart MJ, Ollendick TH. Attention training in socially anxious children: a multiple baseline design analysis. Journal of Anxiety Disorders. 2011;25(7):972-977.

24. Amir N, Taylor CT, Donohue MC. Predictors of response to an attention modification program in generalized social phobia. Journal of Consulting and Clinical Psychology. 2011;79(4):533-541.

25. Li S, Tan J, Qian M, Liu X. Continual training of attentional bias in social anxiety. Behaviour Research and Therapy. 2008;46(8):905-912.

26. Amir N, Weber G, Beard C, Bomyea J, Taylor CT. The effect of a single-session attention modification program on response to a public-speaking challenge in socially anxious individuals.
Journal of Abnormal Psychology. 2008;117(4):860-868.

27. Khodae A, Shokri O, Puklek M, Geravand F, Toulabi S. Factor structure and psychometric properties of the social anxiety scale for adolescents (SASA). International Journal of Behavioral Sciences. 2011;5(3):209-16.

28. MacLeod C, Mathews A, Tata P. Attentional bias in emotional disorders. Journal of Abnormal Psychology. 1986;95(1):15-20.

29. Stark R, Zimmermann M, Kagerer S, Schienle A, Walter B, Weygandt M, et al. Hemodynamic brain correlates of disgust and fear ratings. Neuroimage. 2007;37(2):663-673.

30. Yoon KL, Zinbarg RE. Threat is in the eye of the beholder: Social anxiety and the interpretation of ambiguous facial expressions. Behaviour Research and Therapy. 2007;45(4):839-847.

31. Amir N, Najmi S, Bomyea J, Burns M. Disgust and anger in social anxiety. International Journal of Cognitive Therapy. 2010;3(1):3-10

32. Clark DM, Wells A. A cognitive model of social phobia. Social phobia: Diagnosis, assessment, and treatment. In Heimberg RG, Liebowitz MR, Hope DA, Schneier FR, editors. Social phobia: Diagnosis, assessment, and treatment. New York:The Guilford Press;1995. pp. 69-93.

33. Clark DM. A cognitive perspective on social phobia. In: Crozier R, Alden LE, editors. International handbook of social anxiety: Concepts, research and interventions relating to the self and shyness. New York:John Wiley \& Sons;2001. pp. 405-430. 34. Rapee RM, Heimberg RG. A cognitive-behavioral model of anxiety in social phobia. Behaviour Research and Therapy. 1997;35(8):741-756.

35. MacLeod C, Campbell L, Rutherford E, Wilson E. The causal status of anxiety-linked attentional and interpretive bias. In: Yiend, editors. Cognition, emotion and psychopathology: Theoretical, empirical and clinical directions. Cambrige:Cambrige University Press;2004. pp. 172-219.

36. MacLeod C, Rutherford E, Campbell L, Ebsworthy G, Holker L. Selective attention and emotional vulnerability: Assessing the causal basis of their association through the experimental manipulation of attentional bias. Journal of Abnormal 
Psychology. 2002;111(1):107-123.

37. Mathews A, MacLeod C. Induced processing biases have causal effects on anxiety. Cognition \& Emotion. 2002;16(3):331-354.

38. Heeren A, Peschard V, Philippot P. The causal role of attentional bias for threat cues in social anxiety: A test on a cyber-ostracism task. Cognitive Therapy and Research. 2012;36(5):512-521.

39. MacLeod C, Mathews A. Cognitive bias modification approaches to anxiety. Annual Review of Clinical Psychology. 2012;8:189-217.

40. MacLeod C, Holmes EA. Cognitive bias modification: An intervention approach worth attending to. American Journal of Psychiatry. 2012;169(2):118-120.

41. Beard C. Cognitive bias modification for anxiety: Current evidence and future directions. Expert Review of Neurotherapeutics. 2011;11(2):299-311.

42. Heeren A, Lievens L, Philippot P. How does attention training work in social phobia: disengagement from threat or re-engagement to non-threat?. Journal of Anxiety Disorders. 2011;25(8):1108-1115.

43. Heeren A, Peschard V, Philippot P. The causal role of attentional bias for threat cues in social anxiety: A test on a cyber-ostracism task. Cognitive therapy and research.2012;36(5):512-521.

44. Hallion LS, Ruscio AM. A meta-analysis of the effect of cognitive bias modification on anxiety and depression. Psychological Bulletin. 2011;137(6):940-958.

45. Klumpp H, Amir N. Preliminary study of attention training to threat and neutral faces on anxious reactivity to a social stressor in social anxiety. Cognitive Therapy and Research. 2010;34(3):263-271.

46. Waters AM, Pittaway M, Mogg K, Bradley BP, Pine DS. Attention training towards positive stimuli in clinically anxious children. Developmental Cognitive Neuroscience. 2013;4:77-84.

47. Britton JC, Bar-Haim Y, Clementi MA, Sankin LS, Chen G, Shechner T, et al. Training-associated changes and stability of attention bias in youth: implications for attention bias modification treatment for pediatric anxiety. Developmental Cognitive Neuroscience. 2013;4:52-64.

48. Riemann BC, Kuckertz JM, Rozenman M, Weersing VR, Amir N. Augmentation of youth cognitive behavioral and pharmacological interventions with attention modification: A preliminary investigation. Depression and Anxiety. 2013;30(9):822-888.

49. Bar Haim Y, Morag I, Glickman S. Training anxious children to disengage attention from threat: A randomized controlled trial. Journal of Child Psychology and Psychiatry. 2011;52(8):861-869.

50. Waters AM, Pittaway M, Mogg K, Bradley BP, Pine DS. Attention training towards positive stimuli in clinically anxious children. Developmental Cognitive Neuroscience. 2013;4:77-84.

51. Eldar S, Bar-Haim Y. Neural plasticity in response to attention training in anxiety. Psychological Medicine. 2010;40(4):667-677.

52. Koster EH, Baert S, Bockstaele M, De Raedt R. Attentional retraining procedures: Manipulating early or late components of attentional bias?. Emotion. 2010;10(2):230-236.

53. Browning M, Holmes EA, Murphy SE, Goodwin GM, Harmer CJ. Lateral prefrontal cortex mediates the cognitive modification of attentional bias. Biological Psychiatry. 2010;67(10):919-925.

54. Bögels SM, Mansell W. Attention processes in the maintenance and treatment of social phobia: hypervigilance, avoidance and self-focused attention. Clinical Psychology Review. 2004;24(7):827-856.

55. Buckner JD, Maner JK, Schmidt NB. Difficulty disengaging attention from social threat in social anxiety. Cognitive Therapy and Research. 2010;34(1):99-105.

56. Roy AK, Vasa RA, Bruck M, Mogg K, Bradley BP, Sweeney $\mathrm{M}$, et al. Attention bias toward threat in pediatric anxiety disorders. Journal of the American Academy of Child \& Adolescent Psychiatry. 2008;47(10):1189-1196.

57. Derryberry D, Reed MA. Anxiety-related attentional biases 
and their regulation by attentional control. Journal of Abnormal Psychology. 2002;111(2): 225-236.

58. Bishop SJ. Neural mechanisms underlying selective attention to threat. Annals of the New York Academy of Sciences. 2008;1129(1):141-152.

59. Eysenck MW, Derakshan N. New perspectives in attentional control theory. Personality and Individual Differences. 2011;50(7):955-960.
60. Schaefer SM, Jackson DC, Davidson RJ, Aguirre GK, Kimberg DY, Thompson-Schill SL. Modulation of amygdalar activity by the conscious regulation of negative emotion. Journal of Cognitive Neuroscience. 2002;14(6):913-921.

61. Browning M, Holmes EA, Murphy SE, Goodwin GM, Harmer CJ. Lateral prefrontal cortex mediates the cognitive modification of attentional bias. Biological Psychiatry. 2010;67(10):919-925. 